\title{
RESPONSABILIDADE SOCIAL E AMBIENTAL: ANÁLISE DOS IMPACTOS AMBIENTAIS DE TRANSPORTE DOS RELATÓRIOS ANUAIS E DE SUSTENTABILIDADE DAS EMPRESAS BRASILEIRAS
}

\author{
Mara Vogt* \\ Larissa Degenhart* \\ Fabricia Silva da Rosa** \\ Nelson Hein ${ }^{* * *}$
}

RESUMO: Este estudo objetiva analisar a responsabilidade social e ambiental das empresas brasileiras sobre os impactos ambientais de transporte evidenciados nos Relatórios de Sustentabilidade e Relatórios Anuais. Para tanto, realizou-se uma pesquisa descritiva com abordagem quantitativa por meio de análise documental. A população da pesquisa compreende as 100 empresas pertencentes ao Índice Brasil 100 e a amostra do estudo foi composta por 97 destas empresas. Foram verificados critérios e subcritérios com diferentes escalas sobre o aspecto transporte nos Relatórios Anuais e de Sustentabilidade no período de 2010 a 2013. Calculou-se o peso da informação por meio da entropia e após aplicou-se o método Displaced Ideal - DI para a elaboração dos rankings. A partir dos resultados, constatouse que, no que tange ao ranking, as empresas que evidenciaram ao menos uma informação nos anos analisados sobre o aspecto transporte foram: Copel, CPFL Energia, Eletropaulo, Fibria, Natura, P. Açúcar e Petrobras. Conclui-se que, mesmo que as empresas analisadas apresentaram um aumento gradativo na divulgação de informações ambientais em seus relatórios de um ano para o outro, estas devem se preocupar e divulgar mais informações relacionadas ao aspecto transporte. Além disso, conclui-se que as empresas devem divulgar mais informações em relação aos critérios de avaliação dos impactos e sobre a redução de impactos no que tange às metas. Deste modo, é importante que as empresas divulguem suas informações ambientais sobre o aspecto transporte, com vistas a melhorar sua transparência e responsabilidade social e ambiental perante a sociedade.

PALAVRAS-CHAVE: Evidenciação ambiental; Relatórios de Sustentabilidade e Anuais; Transporte.

Doutorandas em Ciências Contábeis e Administração pela Universidade Regional de Blumenau (FURB), Blumenau (SC), Brasil. E-mail: maravogtcco@gmail.com

** Docente do Departamento de Ciências Contábeis da Universidade Federal de Santa Catarina (UFSC); Doutora em Engenharia de Produção pela Universidade Federal de Santa Catarina (UFSC), Brasil.

*** Doutor em Engenharia de Produção pela Universidade Federal de Santa Catarina (UFSC); Docente do Departamento de Matemática da Universidade Regional de Blumenau (FURB) e Docente permanente no Programa de Pós-graduação em Ciências Contábeis (PPGCC) da Universidade Regional de Blumenau (FURB), Blumenau, (SC), Brasil. 


\section{SOCIAL AND ENVIRONMENTAL RESPONSIBILITY: ANALYSIS OF TRANSPORT ENVIRONMENTAL IMPACTS ON SUSTAINABILIT Y AND YEARLY REPORTS OF BRAZILIAN COMPANIES}

ABSTRACT: Social and environmental responsibility of Brazilian companies on the environmental impact by transport is analyzed through sustainability and yearly reports. A descriptive and quantitative research was undertaken by analyzing documents retrieved from 97 companies of the Index Brazil 100. Criteria and subcriteria with different scales were verified with regard to transport in sustainability and yearly reports between 2010 and 2013. Information weight was calculated by entropy and the Displaced Ideal (DI) method was applied for the elaboration of rankings. Results showed that Copel, CPFL Energia, Eletropaulo, Fibria, Natura, P. Açúcar and Petrobrás were the companies with at least a single information on transport during the years under analysis. Although the companies analyzed had provided a gradual yearly increase in the environmental information in their reports, they should provide more information related to transport. Firms should give more information on their assessment criteria on impacts and their decrease, according to their aims. It is highly relevant that they provide environmental information on transport to improve their transparency and their social and environmental responsibility in society.

KEY WORDS: Environmental evidence; Transport; Sustainability and yearly reports.

\section{INTRODUÇÃO}

Durante os últimos 30 anos, o impacto ambiental das atividades das empresas tornou-se uma preocupação constante dos ambientalistas, legisladores, clientes, autoridades públicas e sociedade em geral. Já nos últimos 15 anos, as empresas aumentaram sua divulgação a respeito da estratégia ambiental para responder às pressões institucionais. Essas estratégias são apresentadas por meio de indicadores que podemos classificar de acordo com o compromisso que representam ao meio ambiente (ALBERTINI, 2013).

De acordo com Meng et al. (2013), o nível de evidenciação ambiental reflete o grau de responsabilidade das empresas. Contudo, devido à assimetria de informação entre as partes interessadas e os altos executivos, as informações sobre 
o meio ambiente podem ser facilmente manipuladas, o que resulta na divulgação seletiva para gerenciar impressões.

Para Boff (2007), a preocupação com a responsabilidade ambiental e social por parte dos governantes e empresas surgiu a partir do momento em que a sociedade começou a ter consciência e até mesmo respeito pelo meio ambiente. A partir desse momento, as empresas e a sociedade passaram a buscar maiores conhecimentos sobre o meio ambiente, que até então, eram ignorados pelo fato dos recursos serem abundantes.

Conforme Harte e Owen (1991) nos anos 90 haviam poucas informações ambientais fornecidas nos Relatórios Anuais e grande parte destas estava relacionada ao desenvolvimento de uma imagem. Já os Relatórios de Sustentabilidade podem ser considerados uma resposta direta às mudanças na sociedade, devido a um público crítico que exige mais ética (DAUB, 2007).

Frente ao exposto destaca-se a seguinte questão que norteia esta pesquisa: Qual o nível de responsabilidade social e ambiental das empresas brasileiras frente aos impactos ambientais de transporte evidenciados nos Relatórios de Sustentabilidade e Relatórios Anuais? No intuito de responder a questão apresentada, o objetivo do estudo consiste em analisar o nível de responsabilidade social e ambiental das empresas brasileiras frente aos impactos ambientais de transporte evidenciados nos Relatórios de Sustentabilidade e Relatórios Anuais. Esta pesquisa justifica-se conforme Eyring et al. (2010), pois os impactos causados pelos transportes apresentaram uma atenção crescente ao longo dos últimos anos e foram reconhecidos como um problema para os responsáveis políticos e cientistas da área. Os gases de escape, até os mais prejudiciais ao meio ambiente, passam a contribuir para a poluição mundial do ar. Além disso, visando a redução dos impactos causados pelos transportes, um número crescente de normas e regulamentos está sendo exigido.

O estudo justifica-se ainda, pois de acordo com Uherek et al. (2010), as emissões causadas pelos transportes terrestres, principalmente dos veículos rodoviários, e em menor quantidade o transporte ferroviário e fluvial, dominam a liberação de gases do efeito estufa, isto é, gases prejudiciais ao meio ambiente.

Deste modo, torna-se oportuno verificar o nível de responsabilidade social e ambiental do cenário brasileiro diante dos impactos ambientes causados por meio 
da utilização do transporte nas empresas e evidenciados nos Relatórios Anuais e de Sustentabilidade, visto que o transporte apresenta muitos impactos negativos para o meio ambiente, sendo muito importante as empresas buscarem alternativas para a redução destes.

\section{EVIDENCIAÇÃO AMBIENTAL}

Mesmo não havendo consenso na profissão e literatura contábil sobre o motivo das empresas divulgarem informações de responsabilidade social, houve um aumento do número de empresas que divulgam voluntariamente suas atividades em seus relatórios (HACKSTON; MILNE, 1996).

Conforme Buhr e Freedman (2001), a evidenciação ambiental possui dimensões sociais e econômicas. Além dos níveis excessivos de emissões prejudiciais ao meio ambiente e à saúde dos indivíduos, têm-se as multas que resultam em uma imagem negativa e podem trazer sérias implicações econômicas para as empresas.

No que diz respeito à evidenciação ambiental, Nossa (2002) destaca que esta pode ser realizada de maneira obrigatória, quando for exigida por leis e regulamentos, ou ainda, de forma voluntária, quando é espontânea, mesmo que seja com base nas diretrizes e orientações.

Até o início do século XX, houve pouca preocupação em preservar ou então recuperar o meio ambiente, visto que a abundância era tanta que os gestores podiam utilizar os recursos naturais como uma fonte inesgotável de matéria-prima a um custo muito baixo ou até mesmo nulo. Na ausência de consciência ambiental, as empresas acabavam por despejar seus resíduos no meio ambiente, sem se preocupar com qualquer tipo de recuperação (COSTA, 2006).

Para Borges, Rosa e Ensslin (2010), a evidenciação das práticas sociais e ambientais pode agregar valor às empresas, pois, além de promover a transparência das informações aos stakebolders, a evidenciação encontra-se em conformidade com as leis. Contudo, a divulgação ambiental ainda não é uma realidade igual para todas as empresas, o que dificulta a padronização entre estas e a avaliação deste contexto.

Além disso, Rosa et al. (2011) salientam que a evidenciação ambiental é utilizada para prestar contas à sociedade. Os gestores das empresas selecionam informações levando em consideração as demandas, a consciência ambiental, 
a responsabilidade profissional e o sistema complexo que envolve o tema. É a evidenciação que possibilita aumentar a comunicação e reduzir a assimetria entre as empresas e as partes interessadas.

A evidenciação das práticas relacionadas ao compromisso com o meio ambiente deveria ser inerente, contudo, na legislação brasileira não há nada que obrigue as empresas a divulgarem. Existe uma tendência mundial dos investidores buscarem por empresas socialmente responsáveis, sustentáveis e rentáveis (OLIVEIRA; MACHADO; BEUREN, 2012).

De acordo com Iatridis (2013), a evidenciação ambiental deve incluir os impactos ambientais das empresas, riscos e incertezas, receitas ou despesas e, ainda, as políticas sobre as questões ambientais. Said, Omar e Abdullah (2013) complementam que a evidenciação demonstra se as atividades estão apresentando impactos significativos no meio ambiente e, se cumprem a legislação, regulamentos e políticas ambientais, se disponibilizam programas para a proteção do meio ambiente e se conservam os recursos naturais. Deste modo, quanto mais a empresa desenvolver iniciativas para a redução dos impactos causados ao meio ambiente por meio de suas atividades, consequentemente maior será a sua divulgação nos Relatórios de Sustentabilidade e Anuais, visto que a apresentação destas informações para a sociedade, partes interessadas, lhe trará inúmeros benefícios.

A evidenciação pode ser conceituada como um meio, ou um conjunto de meios que são utilizados pelas empresas, com a finalidade de apresentar suas práticas ambientais aos stakebolders e, ao mesmo tempo, funciona como ferramenta para que os interessados tomem decisões. Além disso, serve para os investidores fazerem previsões e analisarem o desempenho ambiental da organização (ROSA et al., 2014).

Por fim, segundo Villiers, Low e Samkin (2014), a divulgação voluntária de informações sociais e ambientais é apresentada como um exemplo de regras e estruturas que são implementadas pelas organizações para responder as pressões sociais. Essas pressões incentivam mais as empresas a divulgarem maior quantidade de informações sobre sustentabilidade.

\subsection{IMPACTOS AMBIENTAIS DOS TRANSPORTES}

Os impactos ambientais dos projetos voltados aos transportes evoluíram ao longo dos anos. No entanto, a parte considerada fácil de uma avaliação ambiental 
diz respeito ao processo analítico, ou seja, a identificação dos impactos. Já a parte mais difícil é a avaliação de cada impacto ambiental causado pelos transportes e a síntese destes resultados, a fim de facilitar a tomada de decisão das empresas (TSAMBOULAS; MIKROUDIS, 2000).

Para tanto, a avaliação das iniciativas, projetos e planos para a mitigação dos impactos dos transportes foi realizada no passado por uma variedade de metodologias. Um dos objetivos principais para a realização de uma análise dos impactos ambientais de transportes é a inclusão de questões referentes à qualidade, impactos ambientais no planejamento e, ainda, na tomada de decisão (TSAMBOULAS; MIKROUDIS, 2000).

Segundo Peeters, Szimba e Duijnisveld (2007) em função dos elevados volumes de emissão dos gases de efeito estufa, causados em decorrência da utilização do transporte nas empresas, foram incorporadas políticas destinadas a reduzir o impacto ambiental dos transportes.

O desafio ambiental para os formuladores de políticas voltadas aos transportes é melhorar a eficácia da aplicação dos instrumentos que visam essa amenização de impactos ao meio ambiente (VIEIRA; MOURA; VIEGAS, 2007).

No entanto, conforme Eyring et al. (2010), as emissões de gases poluentes no meio ambiente, causados em decorrência dos transportes, provocam muitos problemas na qualidade do ar. Para tanto, um dos desafios para a sociedade é a redução das emissões ocasionadas pela utilização dos transportes, visto que trazem consequências para a saúde humana por meio da poluição do ar, como também para o ecossistema, isto é, ambientes terrestres e aquáticos. Deste modo, os esforços para a redução das emissões e outros poluentes que provêm dos transportes apresentam considerável vantagem ambiental, pois melhoram a saúde humana, a composição atmosférica e a mudança no clima.

Nesse sentido, Brito (2005) salienta que, com a crescente ocupação urbana no Brasil, verificou-se a degradação da qualidade do ar gerada principalmente pela utilização dos transportes, visto que esta situação tem-se agravado em função do incremento da frota de veículos automotores em circulação, estes que oferecem as maiores contribuições à poluição atmosférica. Assim, como o ar atmosférico é um recurso natural finito e indispensável para a manutenção da vida na Terra, necessita 
constantemente da implementação de ações que visam melhorar sua qualidade e proteger a saúde da população. Exemplo dessa necessidade de controle das emissões atmosféricas conforme Brito (2005) é a implementação de uma rede de monitoramento da qualidade do ar.

Da mesma forma, Uherek et al. (2010) salientam que as emissões causadas pelos transportes nos países industrializados apresentam impactos significativos sobre o meio ambiente e mudanças climáticas. Assim, o controle dessas emissões contribui para a melhoria da qualidade do ar e reduz os impactos na saúde. Contudo, as melhorias esperadas nos veículos, bem como a introdução de biocombustíveis não serão suficientes para compensar o crescimento dos passageiros e transportes no geral.

Diante disso, o Global Reporting Initiative - GRI apresenta um padrão de evidenciação ambiental para diversos aspectos, dentre estes, os transportes. Conforme o GRI (2013), a empresa deve relatar em seus Relatórios de Sustentabilidade e Relatórios Anuais os impactos ambientais significativos relacionados ao transporte, ou seja, aqueles decorrentes do transporte de produtos, outros bens e materiais utilizados nas atividades da empresa, assim como do transporte de seus empregados. Deve relatar também os critérios e as metodologias adotadas, com vistas a determinar quais impactos ambientais são significativos e afetam o meio ambiente.

\section{MATERIAL E MÉTODOS}

Diante do objetivo de analisar o nível de responsabilidade social e ambiental das empresas brasileiras frente aos impactos ambientais de transporte evidenciados nos Relatórios de Sustentabilidade e Relatórios Anuais, realizou-se uma pesquisa descritiva, documental e com abordagem quantitativa.

Para tanto, este estudo caracteriza-se quanto aos objetivos como uma pesquisa descritiva, pois busca-se descrever a evidenciação ambiental das empresas brasileiras frente aos transportes. De acordo com Gil (2010), a pesquisa descritiva objetiva a descrição das características de determinada população e podem ser elaboradas com vistas a identificar possíveis relações entre as variáveis. 
Em relação aos procedimentos de pesquisa, este estudo caracteriza-se como documental, visto que os aspectos de evidenciação ambiental foram coletados nos RS e RA das empresas nos anos analisados. Segundo Marconi e Lakatos (2010), a característica da pesquisa documental é de que a fonte de coleta de dados restringese a documentos, sejam estes escritos ou não, constituindo as fontes primárias, que podem ser realizadas no momento em que o fato ou fenômeno acontece ou até mesmo posteriormente.

No que tange à abordagem do problema, esta pesquisa configura-se como quantitativa. Richardson (1989, p. 29) destaca que o método quantitativo é "frequentemente aplicado nos estudos descritivos, naqueles que procuram descobrir e classificar a relação entre as variáveis, bem como nos que investigam a relação de causalidade entre fenômenos".

O caráter quantitativo é observado na aplicação de métodos matemáticos, como é o caso do Displaced Ideal (solução ideal), que possibilita encontrar as empresas que apresentam melhor evidenciação dos impactos ambientais frente ao aspecto ambiental transportes e as empresas que necessitam aprofundar mais esta questão em seus relatórios e, ainda, a entropia da informação, que permite identificar o peso da informação de cada aspecto ambiental, analisando e identificando dessa forma o aspecto mais evidenciado pelas empresas.

A população da pesquisa compreende todas as empresas pertencentes ao Índice Brasil 100 - IBrX-100 listadas na BM\&FBovespa. Foram utilizadas estas empresas devido ao fato de ser um índice de preços que mede o retorno de uma carteira teórica composta pelas 100 ações que são mais negociadas na Bolsa de Valores de São Paulo em termos de número de negócios e de volume financeiro (BM\&FBOVESPA, 2014). Entretanto, devido ao fato das empresas Bradesco, Klabin e Oi estarem listadas duas vezes, a amostra do estudo foi composta por 97 destas empresas. A partir do Quadro 1 são apresentadas as empresas que compõem a amostra do estudo. 
Quadro 1. Amostra da pesquisa

\begin{tabular}{|c|c|c|c|}
\hline \multicolumn{4}{|l|}{ Empresas } \\
\hline Aes Tietê & CPFL Energia & Itaú Unibanco Holding & PDG Realty \\
\hline $\begin{array}{l}\text { All América Latina } \\
\text { Logística }\end{array}$ & Cyrela Realty & JBS & Petróleo Brasileiro \\
\hline Ambev & Diagnósticos da América & Klabin & Petropar \\
\hline $\begin{array}{l}\text { Anhanguera } \\
\text { Educacional } \\
\text { Participações }\end{array}$ & Duratex & Kroton Educacional & Porto Seguro \\
\hline Arteris & $\begin{array}{l}\text { Ecorodovias } \\
\text { Infraestrutura e } \\
\text { Logística }\end{array}$ & Light & Qualicorp \\
\hline B2W Companhia Digital & Eletrobrás Participações & LLX Log & Raia Drogasil \\
\hline $\begin{array}{l}\text { BCO Estado do Rio } \\
\text { Grande do Sul }\end{array}$ & $\begin{array}{l}\text { Eletropaulo Metrop. } \\
\text { Elet. São Paulo }\end{array}$ & Localiza Rent a Car & Randon \\
\hline BM\&FBovespa & Embraer & Lojas Americanas & Rossi Residencial \\
\hline BR Malls Participações & EDP - Energias do Brasil & Lojas Renner & Sabesp \\
\hline BR Properties & Eneva & M. Dias Branco & CIA Siderúrgica \\
\hline BCO Bradesco & Equatorial Energia & Magazine Luiza & Souza Cruz \\
\hline BCO Brasil & Estácio Participações & Marcopolo & Sul América \\
\hline BCO Santander & $\begin{array}{l}\text { Even Construtora e } \\
\text { Incorporadora }\end{array}$ & Marfrig Global Foods & $\begin{array}{l}\text { Suzano Papel e } \\
\text { Celulose }\end{array}$ \\
\hline Bradespar & $\begin{array}{l}\text { Ez Tec Empreend. e } \\
\text { Participações }\end{array}$ & $\begin{array}{l}\text { Mills Estruturas e } \\
\text { Serviços de Engenharia }\end{array}$ & $\begin{array}{l}\text { Transmissora Aliança de } \\
\text { Energia Elétrica }\end{array}$ \\
\hline Braskem & Fibria Celulose & Minerva & Telefônica Brasil S.A \\
\hline BRF-Brasil Foods & Gafisa & $\begin{array}{l}\text { MMX Mineração e } \\
\text { Metálicos }\end{array}$ & TIM Participações \\
\hline $\begin{array}{l}\text { Brookfield } \\
\text { Incorporações }\end{array}$ & Gerdau & $\begin{array}{l}\text { MRV Engenharia e } \\
\text { Participações }\end{array}$ & Totvs \\
\hline CCR & Gerdau Metalúrgica & $\begin{array}{l}\text { Multiplan - Empreend } \\
\text { Imobiliários }\end{array}$ & Tractebel Energia \\
\hline $\begin{array}{l}\text { CIA Energética de Minas } \\
\text { Gerais - Cemig }\end{array}$ & $\begin{array}{l}\text { Gol Linhas Aéreas } \\
\text { Inteligentes }\end{array}$ & Multiplus & Ultrapar Participações \\
\hline Cetip & $\begin{array}{l}\text { HRT Participações em } \\
\text { Petróleo }\end{array}$ & Natura Cosméticos & $\begin{array}{l}\text { Usinas Sid de Minas } \\
\text { Gerais }\end{array}$ \\
\hline CIA Hering & Hypermarcas & Odontoprev & Vale \\
\hline Cielo & $\begin{array}{l}\text { Iguatemi Empresa de } \\
\text { Shopping Centers }\end{array}$ & OGX Petróleo e Gás & Valetron \\
\hline $\begin{array}{l}\text { CIA Saneamento de } \\
\text { Minas Gerais - Copasa }\end{array}$ & Iochpe Maxion & OI & Valid \\
\hline $\begin{array}{l}\text { CIA Paranaense de } \\
\text { Energia - Copel }\end{array}$ & $\begin{array}{l}\text { Itausa Investimentos } \\
\text { Itaú }\end{array}$ & Pão de Açúcar - CBD & Weg \\
\hline Cosan & & & \\
\hline
\end{tabular}

Fonte: Dados da pesquisa. 
Os Relatórios Anuais e de Sustentabilidade foram baixados diretamente no sítio das empresas pertencentes à amostra e, nestes relatórios, foi verificado o aspecto transporte, seus critérios e subcritérios, de acordo com as diretrizes do GRI do ano de 2013. Elaborou-se uma planilha eletrônica por meio da ferramenta Microsoft Excel versão 2010, na qual foi preenchido o nível de cada critério e subcritério analisado de cada empresa.

Ressalta-se que esses critérios e subcritérios apresentam diferentes escalas para expressar ordem entre os níveis, de acordo com o desempenho de cada critério, o que possibilita a atribuição de até oito níveis distintos. As escalas foram criadas a partir da interpretação de todas as informações apresentadas sobre o aspecto transporte nas diretrizes do GRI (2013): impactos ambientais significativos decorrentes do transporte de produtos e outros bens e materiais usados nas operações da organização, bem como do transporte de seus empregados. Além disso, Crespo Soler et al. (2011) em seu estudo criaram as escalas para cada um dos critérios e subcritérios analisados neste estudo.

$\mathrm{O}$ aspecto ambiental relacionado ao transporte possui três critérios e subcritérios. Os critérios são: Impactos dos transportes, Critérios de avaliação de impactos e Redução de impactos. O primeiro critério apresentado, isto é, Impactos dos transportes, possui os seguintes subcritérios: Transportes utilizados pela empresa, Transportes utilizados para fins logísticos e Transportes utilizados para transporte do público interno.

O subcritério Transportes utilizados pela empresa foi dividido em Tipo de informação, que possui uma escala de oito níveis (N1 a N8), que vai de nenhuma informação até informação Descritiva, Quantitativa e Monetária (D/Q/M). A Abrangência diz respeito se a empresa relata (Sim: N2) ou (Não: N1) o tipo de fonte causadora dos transportes utilizados pela empresa. Nos outros dois subcritérios, Transportes utilizados para fins logísticos e Transportes utilizados para transporte do público interno, foi analisado se a empresa relata os impactos dos transportes utilizados para fins logísticos (locomoção de público interno) que, por sua vez, está dividida em (N1 e N2), sendo que (N1) representa Não e (N2) Sim.

Por meio do critério Critérios de avaliação dos impactos foi verificado se a empresa divulga os critérios utilizados para avaliar os impactos dos transportes, 
preenchendo assim com o nível 2 (N2). Caso as empresas não apresentarem nos RS e RA esta divulgação, este critério adquiriu o nível 1 (N1). Além destes critérios, tem-se a Redução de impactos que são provocados pelos transportes. Este critério foi subdividido pelos subcritérios Tipo e Meta de redução. O subcritério Tipo foi dividido em escalas (N1 e N2). Considera-se (N1) se a empresa não relata a redução de impactos por tipo de fonte causadora e (N2) se relata. No que tange à Meta de redução buscou-se identificar o percentual de metas de redução de impactos de transportes do ano anterior que foram atendidas no último ano que vai de $0 \%$ a $100 \%$, sendo que $0 \%$ representa o nível (N1) e o nível (N5) é utilizado quando a empresa possui $100 \%$ de metas.

A importância dos níveis é representada a partir das cores: vermelho, amarelo e verde, sendo que o vermelho diz respeito a um nível considerado comprometedor e a cor verde um excelente nível de divulgação para as empresas. Para facilitar o entendimento dos critérios e subcritérios analisados, no Quadro 2 apresenta-se a descrição destes sobre o aspecto transporte e sua devida mensuração.

Quadro 2. Descrição e mensuração dos critérios e subcritérios do aspecto transporte

\begin{tabular}{|c|c|c|c|c|c|c|c|c|c|}
\hline \multirow{3}{*}{$\begin{array}{c}\text { ASPECTO - Critérios e Subcritérios } \\
\text { 5 TRANSPORTES }\end{array}$} & \multirow{3}{*}{ Descrição } & \multicolumn{8}{|c|}{ Mensuração } \\
\hline & & \multicolumn{8}{|c|}{ Escala - nive is } \\
\hline & & N1 & N2 & N3 & N4 & N5 & N6 & N7 & N8 \\
\hline \multicolumn{10}{|l|}{5.1 Impactos dos transportes } \\
\hline \multicolumn{10}{|l|}{ 5.1.1 Transportes utilizados pela empresa } \\
\hline 5.1.1.1 Tipo de informação & $\begin{array}{l}\text { Qual o tipo de informação prestada? Descritiva (D), } \\
\text { Monetária (M), Quantitativa (Q). }\end{array}$ & VADA & D & м & Q & $\mathbf{D} / \mathbf{M}$ & $\mathbf{D} / \mathbf{Q}$ & $\mathbf{Q} / \mathbf{M}$ & $\mathbf{D} / \mathbf{Q} / \mathbf{M}$ \\
\hline 5.1.1.2 Abrangência & Relata o tipo de fonte causadora? & NĀO & SIM & & & & & & \\
\hline 5.1.2 Transportes utilizados para fins logísticos & $\begin{array}{l}\text { Relata os impactos dos transportes utilizados para fins } \\
\text { logisticos? }\end{array}$ & NĀO & SIM & & & & & & \\
\hline 5.1.3 Transportes utilizados para transporte do público interno & $\begin{array}{l}\text { Relata os impactos dos transportes utilizados para a } \\
\text { locomoção de público interno? }\end{array}$ & NĀO & SIM & & & & & & \\
\hline 5.2 Critérios de avaliação de impactos & $\begin{array}{l}\text { Divulga os critérios utilizados para avaliar os impactos } \\
\text { dos transportes? }\end{array}$ & NÃO & SIM & & & & & & \\
\hline \multicolumn{10}{|l|}{5.3 Redução de impacto } \\
\hline 5.3.1 Tipo & $\begin{array}{l}\text { Relata a redução de impactos por tipo de fonte } \\
\text { causadora? }\end{array}$ & NĀO & SIM & & & & & & \\
\hline 5.3.2 Meta & $\begin{array}{l}\text { \% de metas de redução de impactos de transportes do } \\
\text { ano anterior que foram atendidas no último ano. }\end{array}$ & $0 \%$ & $25 \%$ & $\mathbf{5 0} \%$ & $75 \%$ & $100 \%$ & & & \\
\hline
\end{tabular}

Fonte: Adaptado do GRI (2013).

No que se refere ao período de análise, em função da publicação dos relatórios, tanto Relatório Anual - RA quanto Relatório de Sustentabilidade - RS ocorrerem com mais frequência nas empresas analisadas nos últimos anos, neste 
estudo foi analisado o período de 2010 a 2013. A coleta de dados, isto é, dos relatórios analisados, foi realizada em março e abril de 2014, referente ao período de 2010 a 2012 e, em outubro e novembro de 2014 foram baixados os relatórios de 2013. Salienta-se que a planilha foi alimentada a partir dos níveis verificados para cada empresa da amostra, em cada ano analisado e referente a cada relatório verificado de forma individual.

\subsection{MÉTODO DISPLACED IDEAL}

O método Displaced Ideal, conforme Zeleny (1974), objetiva a criação de rankings. Esta metodologia adota por critérios a menor distância de um determinado ponto do seu cenário ideal. O cenário ideal é o ponto máximo encontrado dentro do conjunto analisado.

Deste modo, determina-se a solução ideal $(0,0000)$, como sendo aquela que apresenta o maior valor em cada um dos conjuntos. Depois de encontrado o valor ideal de cada um dos conjuntos, possui-se o cenário ideal. Na sequência a partir dos valores das distâncias, estes são ordenados de forma crescente, elaborando-se assim o ranking. Utiliza-se a classificação em ordem crescente, visto que quanto maior for a distância, significa que o ponto analisado está mais próximo do cenário ideal. Por fim, o método Displaced Ideal auxilia na tomada de decisões multiobjetivas (ZENELY, 1974; 1982).

Diante do exposto, para a realização da análise dos dados utilizou-se a entropia da informação, visando obter um peso, este que foi utilizado para a aplicação do método Displaced Ideal (solução ideal). A partir desse método, elaborou-se um ranking sobre as informações ambientais divulgadas pelas empresas analisadas sobre o aspecto transporte em seus relatórios.

\section{RESULTADO E DISCUSSÃO}

Esta seção apresenta o ranking das empresas brasileiras analisadas sobre o aspecto ambiental transporte, verificado nos Relatórios de Sustentabilidade 
e Relatórios Anuais dos quatro anos analisados. Ressalta-se que no ranking são apresentadas somente as empresas que possuíam ao menos uma informação em um de seus relatórios e foi realizada a soma por pontos corridos da sua posição. Além disso, destaca-se que os resultados em relação aos níveis (RS e RA) foram somados em todos os anos para a aplicação do método. A partir do Quadro 3 é possível verificar a quantidade de empresas que divulgavam informações em cada ano analisado sobre o aspecto transporte.

Quadro 3. Empresas que evidenciaram informações ambientais sobre transporte

\begin{tabular}{|l|c|c|c|c|}
\hline Relatórios & $\mathbf{2 0 1 0}$ & $\mathbf{2 0 1 1}$ & $\mathbf{2 0 1 2}$ & $\mathbf{2 0 1 3}$ \\
\hline (RS+RA) COM Informações Ambientais sobre Transporte & 17 & 20 & 27 & 31 \\
\hline (RS+RA) SEM Informações Ambientais sobre Transporte & 80 & 77 & 70 & 66 \\
\hline TOTAL & \multicolumn{3}{|c|}{97} \\
\hline
\end{tabular}

Fonte: Dados da pesquisa.

Por meio do Quadro 3 nota-se que no ano de 2010 houve o menor número de empresas que apresentavam ao menos uma informação ambiental sobre o aspecto transporte. Esse número foi aumentando de um ano para o outro, visto que em 2011 já eram 20 empresas que apresentaram relatórios com ao menos uma informação, 2012 eram 27 empresas e em 2013 foram 31 organizações. De acordo com Daub (2007), os relatórios são considerados o "cartão de visita" das empresas.

Este fato pode ter ocorrido em razão de que as empresas começaram a se preocupar cada vez mais com a evidenciação ambiental sobre os transportes e divulgavam estas informações aos interessados, para melhorar sua imagem perante a sociedade. A partir da Tabela 1 apresenta-se o ranking do ano de 2010, contendo as empresas que evidenciaram ao menos uma informação sobre o aspecto transporte nos Relatórios Anuais e de Sustentabilidade. Os scores apresentados nas Tabelas 1, 2, 3 e 4 foram obtidos a partir da aplicação do método da entropia da informação e posterior utilização do método Displaced Ideal, este que visa o desenvolvimento de rankings. 
Tabela 1. Ranking de evidenciação dos impactos ambientais sobre transporte do ano de 2010

\begin{tabular}{ccc|ccc}
\hline Empresa & Score & Posição & Empresa & Score & Posição \\
\hline Copel & 0,1177 & 1 & Suzano Papel & 0,6044 & 9 \\
Ambev & 0,2656 & 2 & BRF - Brasil Foods & 0,6050 & 11 \\
\hline Eletropaulo & 0,3427 & 3 & CCR & 0,6056 & 12 \\
Klabin & 0,3427 & 3 & Sul América & 0,6061 & 13 \\
Duratex & 0,5442 & 5 & CPFL Energia & 0,6080 & 14 \\
\hline P. Açúcar & 0,5442 & 5 & Gol & 0,6092 & 15 \\
\hline Petrobras & 0,6024 & 7 & Natura & 0,6092 & 15 \\
\hline Tractebel & 0,6024 & 7 & Fibria & 0,6712 & 17 \\
\hline Braskem & 0,6044 & 9 & & & \\
\hline
\end{tabular}

Fonte: Dados da pesquisa.

$\mathrm{Na}$ Tabela 1 verifica-se que apenas 17 empresas apresentavam divulgações ambientais sobre transportes neste ano em seus relatórios, ou seja, um número significativamente baixo, se comparar a quantidade de empresas analisadas (97).

Nota-se que a empresa Copel liderou o ranking neste ano, seguida das empresas Ambev, Eletropaulo e Klabin. Estas empresas foram as que apresentaram valor mais próximo de zero, o que é considerado a solução (evidenciação ambiental) mais perto do ideal, a partir do método utilizado. Contudo, vale destacar que as empresas Eletropaulo e Klabin apresentaram o mesmo score, obtendo a $3^{\mathrm{a}}$ posição no ranking. Da mesma forma, as empresas Duratex e P. Açúcar ocuparam a $5^{\mathrm{a}}$ posição, a Petrobras e Tractebel a $7^{\mathrm{a}}$ colocação, as empresas Braskem e Suzano Papel a $9^{\text {a }}$ colocação e, por fim, as empresas Gol e Natura ficaram com a $15^{a}$ posição.

Em relaçãoàs informações divulgadas sobreoaspecto transporte pelaempresa Copel (Companhia Paranaense de Energia) em seu Relatório de Sustentabilidade e Anual, tem-se que a frota de veículos que é destinada às atividades operacionais e ao transporte dos funcionários a serviço da organização é adquirida com preferência para modelos que utilizam álcool como combustível. Entretanto, se necessária a aquisição de algum modelo a diesel, a empresa busca atender às exigências legais em relação à emissão de poluentes. Além disso, o setor de transporte e demais setores 
que fazem uso de veículos realizam manutenções operativas, preventivas e corretivas, principalmente no que diz respeito ao catalisador e ao sistema de escapamento, devido ao controle da emissão de poluentes.

Já no que diz respeito à Ambev (Companhia de Bebidas das Américas), ao analisar separadamente as ações contidas nos relatórios dessa empresa, constatouse que esta divulga diferentes informações. Dessa forma, por meio do Quadro 4 são evidenciadas as informações ambientais sobre o aspecto transporte.

Quadro 4. Informações ambientais divulgadas pela empresa Ambev sobre transporte

\begin{tabular}{|l|c|c|c|c|c|c|c|}
\hline \multirow{2}{*}{ Transportes } & \multicolumn{4}{|c|}{ Transportes utilizados pela empresa } & \multicolumn{2}{c|}{$\begin{array}{c}\text { Reduçãa de de } \\
\text { de } \\
\text { impacto }\end{array}$} \\
\cline { 2 - 8 } & $\begin{array}{l}\text { Tipo de } \\
\text { Informação }\end{array}$ & Abrangência & $\begin{array}{c}\text { Fins } \\
\text { Logísticos }\end{array}$ & $\begin{array}{l}\text { Público } \\
\text { Interno }\end{array}$ & impactos & Tipo & Meta \\
\hline $\begin{array}{l}\text { Escala dos } \\
\text { níveis }\end{array}$ & N1-N8 & N1-N2 & N1-N2 & N1-N2 & N1-N2 & $\begin{array}{c}\text { N1- } \\
\text { N2 }\end{array}$ & $\begin{array}{c}\text { N1- } \\
\text { N5 }\end{array}$ \\
\hline $\begin{array}{l}\text { Relatório de } \\
\text { Sustentabilidade }\end{array}$ & 2 & 2 & 2 & 2 & 2 & 2 & 5 \\
\hline Relatório Anual & 6 & 2 & 2 & 2 & 2 & 2 & 1 \\
\hline
\end{tabular}

Fonte: Dados da pesquisa.

De acordo com o Quadro 4, nota-se que a empresa possuía mais divulgações quanto ao tipo de informação em seu Relatório Anual, visto que apresentou informações Descritivas e Quantitativas (D/Q), ou seja, o nível 6. Já no Relatório de Sustentabilidade, apenas divulgou informações Descritivas (D), que corresponde ao nível 2. Outra informação ambiental que merece destaque é em relação à meta de redução de impactos, pois, dessa vez, no Relatório de Sustentabilidade houve um maior nível de divulgação, ou seja, a empresa apresentou uma meta de $100 \%$ de redução dos impactos sobre transportes do ano anterior que foram atendidas no último ano (N5). No seu Relatório Anual não apresentou nenhuma meta de redução. Diante desses achados, Meng et al. (2013) ressaltam que o nível de evidenciação ambiental reflete o grau de responsabilidade ambiental das empresas.

Ainda, ressalta-se que as demais informações divulgadas pela empresa, isto é, a Abrangência, os Transportes utilizados para fins logísticos, para transporte 
do público interno, os Critérios de avaliação de impactos e o Tipo de redução de impactos, apresentaram o nível 2 (N2), o que indica que as empresas apresentam essas informações nos relatórios analisados. Na Tabela 2 apresenta-se o ranking de evidenciação dos impactos ambientais sobre transporte do ano de 2011.

Tabela 2. Ranking de evidenciação dos impactos ambientais sobre transporte do ano de 2011

\begin{tabular}{cccccc}
\hline Empresa & Score & Posição & Empresa & Score & Posição \\
\hline Copel & 0,1078 & 1 & Petrobras & 0,6672 & 11 \\
\hline Natura & 0,1619 & 2 & Itaú Unibanco & 0,6688 & 12 \\
\hline Ambev & 0,3710 & 3 & Sul América & 0,6693 & 13 \\
\hline Klabin & 0,3715 & 4 & Tractebel & 0,6693 & 13 \\
\hline Eletropaulo & 0,3781 & 5 & Suzano Papel & 0,6705 & 15 \\
\hline Embraer & 0,3810 & 6 & CPFL Energia & 0,6707 & 16 \\
\hline Ecorodovias & 0,5943 & 7 & Vale & 0,6725 & 17 \\
\hline BRF - Brasil Foods & 0,5973 & 8 & Sid Nacional & 0,7436 & 18 \\
\hline P. Açúcar & 0,5999 & 9 & Fibria & 0,7436 & 18 \\
\hline BM\&FBovespa & 0,6672 & 10 & Marcopolo & 0,7436 & 18 \\
\hline
\end{tabular}

Fonte: Dados da pesquisa.

Por meio da Tabela 2 verifica-se que somente 20 das 97 empresas analisadas apresentavam divulgações ambientais sobre transporte em 2011 em seus relatórios. Novamente um número relativamente baixo, contudo, já foi maior que no ano de 2010.

Neste ano, a empresa Copel novamente configurou como a primeira posicionada no ranking, sendo a Natura a segunda e a Ambev, neste ano, a terceira. Destaca-se também que em 2011 apenas cinco empresas apresentaram os mesmos scores, isto é, a Sul América e a Tractebel que ocuparam a $13^{a}$ posição e a Sid Nacional, Fibria e Marcopolo com a $18^{\mathrm{a}}$ colocação.

No Gráfico 1 apresenta-se a evidenciação ambiental da empresa Natura (setor de cosméticos e higiene), segunda colocada no ranking no ano de 2011, sobre o aspecto transporte em seu Relatório de Sustentabilidade e Relatório Anual. 


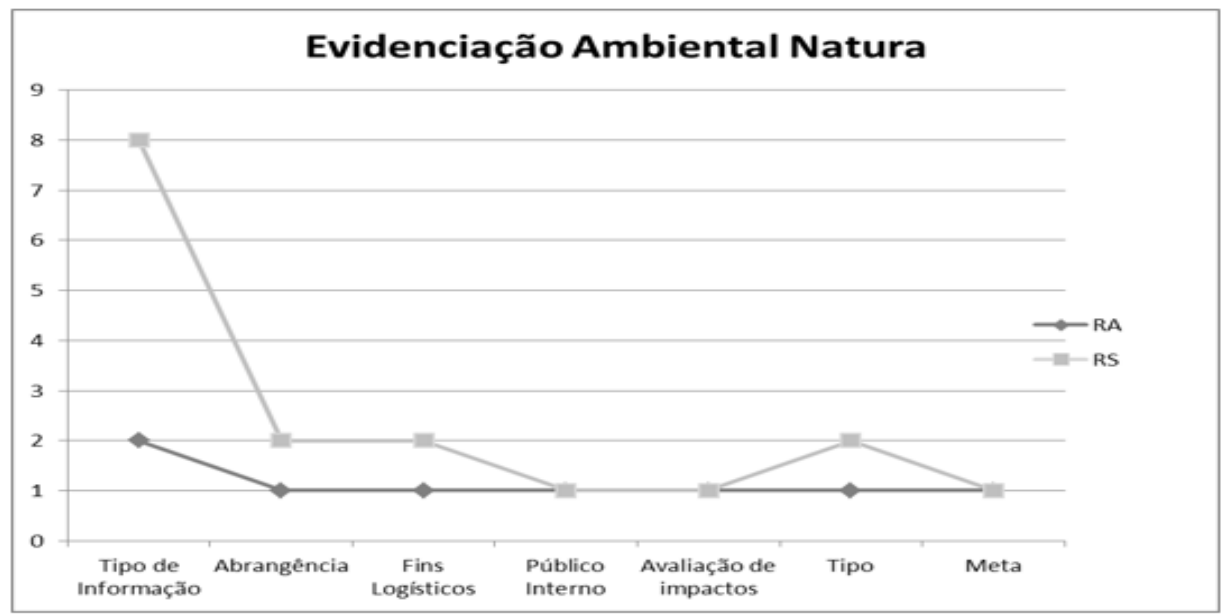

Gráfico 1. Evidenciação ambiental da empresa Natura sobre o aspecto transporte no ano de 2011 Fonte: Dados da pesquisa.

Ressalta-se que optou-se em analisar a empresa Natura, devido ao fato da Copel, primeira colocada no ranking possuir um relatório unificado, ou seja, Relatório Anual e Relatório de Sustentabilidade em um mesmo documento, apresentando dessa forma, as mesmas informações nos dois relatórios, cenário diferente da empresa Natura.

Conforme o Gráfico 1 observa-se que a empresa Natura somente obteve níveis iguais em relação ao critério Critérios de avaliação de impactos e do subcritério Transportes utilizados para público interno, sendo que não evidenciou informações nos relatórios sobre esse critério e subcritério. Há uma grande diferença no que diz respeito ao tipo de informação, visto que no Relatório de Sustentabilidade a empresa divulgou informações Descritivas, Quantitativas e Monetárias (D/Q/M) e no Relatório Anual apenas divulgou informações Descritivas (D).

No que tange aos demais critérios e subcritérios analisados (Abrangência; Transporte utilizado pela empresa para fins logísticos; Tipo e metas de redução dos impactos), nota-se que a empresa divulgou estas informações em seu Relatório de Sustentabilidade e o contrário foi verificado no Relatório Anual.

Diante disso, infere-se que nesta empresa o RS apresentou mais informações ambientais em relação ao aspecto transporte. Nesse sentido, contribuindo com esse 
achado, Lungu, Caraiani e Dascalu (2007) salientam que cada vez mais as empresas estão divulgando seus Relatórios de Sustentabilidade que abordam informações referentes ao impacto social, ambiental e econômico das atividades desenvolvidas pelas empresas com vistas a impulsionar a estratégia e seu crescimento.

$\mathrm{Na}$ Tabela 3 apresenta-se o ranking de evidenciação dos impactos ambientais sobre transporte do ano de 2012. Ressalta-se que nesta tabela são apresentadas apenas as empresas que possuíam algum dado ambiental sobre transporte neste ano.

Tabela 3. Ranking de evidenciação dos impactos ambientais sobre transporte do ano de 2012

\begin{tabular}{cccccc}
\hline Empresa & Score & Posição & Empresa & Score & Posição \\
\hline Even & 0,0716 & 1 & BRF - Brasil Foods & 0,5331 & 15 \\
\hline Copasa & 0,1042 & 2 & Eletrobras & 0,5331 & 15 \\
Copel & 0,1042 & 2 & Petrobras & 0,5911 & 17 \\
\hline Natura & 0,2669 & 4 & Light & 0,5924 & 18 \\
\hline ItauUnibanco & 0,3309 & 5 & Eletropaulo & 0,5939 & 19 \\
\hline Cosan & 0,3321 & 6 & Tractebel & 0,5939 & 19 \\
\hline Cielo & 0,3351 & 7 & Telefônica Brasil & 0,5956 & 21 \\
\hline Sul América & 0,3363 & 8 & Vale & 0,5961 & 22 \\
\hline Embraer & 0,3371 & 9 & CPFL energia & 0,5973 & 23 \\
Weg & 0,3371 & 9 & P. Açúcar & 0,5973 & 23 \\
\hline Lojas Renner & 0,3410 & 11 & Fibria & 0,6607 & 25 \\
\hline Bco Brasil & 0,3972 & 12 & Magazine Luiza & 0,6607 & 25 \\
\hline Cemig & 0,5238 & 13 & Marcopolo & 0,6607 & 25 \\
\hline Ecorodovias & 0,5249 & 14 & & & \\
\hline
\end{tabular}

Fonte: Dados da pesquisa.

Segundo a Tabela 3 pode-se verificar que neste ano foram 27 que apresentaram ao menos uma informação ambiental sobre transporte em seus relatórios. Desta vez, a empresa Even apresentou a solução mais próxima do ideal, ou seja, a maior evidenciação ambiental sobre transporte neste ano, seguida das 
empresas Copasa, Copel e Natura.

Destaca-se que novamente a empresa Copel, segunda colocada no ranking e a empresa Natura, quarta colocada, ficaram entre as empresas que mais evidenciaram sobre transporte e seus impactos ambientais, bem como a redução destes em seus relatórios.

A empresa Even, do ramo da Construção Civil, que liderou o ranking em 2012, apresenta em seus relatórios (RS e RA) que investiu no ano de 2012 aproximadamente $\mathrm{R} \$ 11$ milhões em ações destinadas ao controle e prevenção de questões voltadas à sustentabilidade. Dentre estes investimentos divulgam as ações de controle, a auditoria do Inventário de Emissões de Gases de Efeito Estufa (GEE) e as ações de transporte e destinação de resíduos. Além disso, busca oferecer aos habitantes ar sem poluição, água potável, energia suficiente, serviços de saúde e transporte eficiente. Dessa forma, a falta ou a deficiência de qualquer um desses itens apresenta impactos econômicos, ambientais e sociais.

Ainda, realizam a medição das emissões geradas pelo transporte dos seus colaboradores, por via terrestre e aérea. No processo de construção dos empreendimentos, não utilizam substâncias com potencial de destruição da camada de ozônio, contribuindo assim com o meio ambiente.

No entanto, o desempenho da empresa Even nos anos de 2010, 2011 e 2013 foi baixo, visto que não apresentou informações ambientais sobre o aspecto transporte em seus relatórios nestes anos analisados, ficando assim com o nível 1 (N1) de divulgação ambiental e entre as seguintes colocações no ranking: $48^{\mathrm{a}}, 50^{\mathrm{a}} \mathrm{e}$ $52^{\mathrm{a}}$ respectivamente. Contudo, divulgou para a sociedade somente nos anos de 2011 e 2012 o Relatório de Sustentabilidade e Relatório Anual unificado, isto é, o mesmo relatório em um documento único e nos demais anos não evidenciou relatórios, o que refletiu nestas posições no ranking. Por meio da Tabela 4 é evidenciado o ranking dos impactos ambientais sobre transporte do ano de 2013.

Tabela 4. Ranking de evidenciação dos impactos ambientais sobre transporte do ano de 2013

(Continua)

\begin{tabular}{cccccc}
\hline Empresa & Score & Posição & Empresa & Score & Posição \\
\hline P. Açúcar & 0,0804 & 1 & Oi & 0,6558 & 17 \\
Energias & 0,1109 & 2 & Vale & 0,6569 & 18 \\
\hline
\end{tabular}


(Conclusão)

\begin{tabular}{cccccc}
\hline Empresa & Score & Posição & Empresa & Score & Posição \\
\hline Petrobras & 0,2321 & 3 & Marfrig & 0,6591 & 19 \\
\hline Bco Brasil & 0,3655 & 4 & Marcopolo & 0,6591 & 19 \\
\hline Itaú Unibanco & 0,3744 & 5 & AES Tietê & 0,6602 & 21 \\
\hline Lojas Renner & 0,3798 & 6 & Banrisul & 0,6602 & 21 \\
\hline Porto Seguro & 0,5792 & 7 & CPFL Energia & 0,6602 & 21 \\
\hline Ecorodovias & 0,5879 & 8 & Cosan & 0,6602 & 21 \\
\hline Eletrobrás & 0,5879 & 8 & Cyrela Realt & 0,6602 & 21 \\
\hline Natura & 0,5882 & 10 & Eletropaulo & 0,6602 & 21 \\
\hline Banco Bradesco & 0,5898 & 11 & Embraer & 0,6602 & 21 \\
\hline Braskem & 0,5898 & 11 & Fibria & 0,6602 & 21 \\
\hline CCR & 0,5898 & 11 & Itausa & 0,6602 & 21 \\
\hline Copasa & 0,5898 & 11 & Santander & 0,6602 & 21 \\
\hline Copel & 0,5898 & 11 & Duratex & 0,7253 & 31 \\
\hline Cemig & 0,5898 & 11 & & & \\
\hline
\end{tabular}

Fonte: Dados da pesquisa.

De acordo com os dados apresentados na Tabela 4, percebe-se que a empresa P. Açúcar liderou o ranking de evidenciação de impactos ambientais sobre transporte em 2013. Essa empresa divulga informações do tipo Descritivo e Quantitativo (D/Q), ou seja, o nível 6 de evidenciação ambiental. Já quanto à abrangência, relata o tipo de fonte causadora e, em relação aos impactos dos transportes utilizados para a locomoção de público interno, a empresa relata esta informação e expõem em seus relatórios que as emissões diretas de gases de efeito estufa foram equivalentes a 705,71 toneladas de $\mathrm{CO}_{2}$ neste ano.

Dentre os esforços para a diminuição dos impactos ambientais causados a partir das atividades desenvolvidas pela empresa, tem-se a redução da emissão de Gases de Efeito Estufa (GEE), a redução do consumo de energia e dos riscos com o transporte de produtos. No transporte de materiais, houve uma grande diminuição das emissões, que se deve principalmente à migração para o transporte terceirizado. 
Expõem ainda que os impactos ambientais são monitorados, com vistas a criar iniciativas para mitigá-los e tornar as atividades mais sustentáveis. Dessa forma, infere-se que a empresa P. Açúcar está preocupada com o meio ambiente, no que diz respeito ao aspecto transporte e apresenta a solução mais próxima do ideal de evidenciação ambiental, visto que obteve o score de 0,0804 .

Outro fato que chama a atenção neste ano é a posição das empresas, pois 06 das 31 que evidenciaram ao menos uma informação ambiental sobre transporte

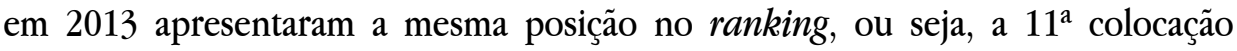
(Banco Bradesco, Braskem, CCR, Copasa, Copel e Cemig). Além disso, 10 empresas evidenciaram a mesma quantidade de informações em seus relatórios, obtendo a mesma posição no ranking, isto é, $21^{a}$ colocação, sendo as empresas: AES Tietê, Banrisul, CPFL Energia, Cosan, Cyrela Realt, Eletropaulo, Embraer, Fibria, Itausa e Santander. Contudo, vale destacar que o fato destas empresas terem apresentado a mesma posição no ranking não quer dizer que divulgaram os mesmos níveis em relação aos critérios e subcritérios ambientais analisados sobre transporte.

No geral pode-se perceber a partir da análise dos quatro rankings de evidenciação dos impactos ambientais sobre o aspecto transporte apresentados no decorrer da análise dos dados que nem sempre as mesmas empresas estão presentes nos rankings, o que demonstra que de um ano para o outro as empresas não apresentaram uma continuidade com as informações apresentadas nos seus relatórios e até mesmo passaram a não divulgar o Relatório de Sustentabilidade e Relatório Anual em algum dos anos analisados. Diante destes resultados, nota-se que as empresas ainda não apresentam uma constante preocupação em divulgar informações ambientais sobre o aspecto transporte em seus relatórios.

Além disso, dentre as empresas que apresentaram alguma informação sobre os critérios e subcritérios ambientais analisados o nível de evidenciação ainda apresenta-se muito baixo, necessitando uma atenção especial das empresas para a divulgação dos impactos causados ao meio ambiente por meio da utilização dos transportes, bem como a redução destes, pois sabe-se o quanto o transporte contribui para a poluição atmosférica.

Segundo Borges, Rosa e Ensslin (2010), a evidenciação social e ambiental pode agregar valor às empresas, visto que além de promover a transparência das 
informações aos investidores, encontra-se em conformidade com as leis. Além disso, os autores expõem que a evidenciação ambiental ainda não é uma realidade igual para todas as organizações, dificultando a evidenciação padronizada entre estas, assim como a avaliação das informações divulgadas, o que corrobora com os achados da presente pesquisa. Contudo, Oliveira, Machado e Beuren (2012) salientam que na legislação brasileira não há nada que obrigue as empresas a divulgarem. Porém, existe uma tendência mundial dos investidores buscarem pelas empresas socialmente responsáveis, sustentáveis e rentáveis.

\section{CONSIDERAÇÕES FINAIS}

Este estudo analisou, dentre um conjunto de critérios e subcritérios ambientais, o nível de responsabilidade social e ambiental das empresas brasileiras frente aos impactos ambientais de transporte evidenciados nos Relatórios de Sustentabilidade e Relatórios Anuais. Para a consecução do objetivo proposto, procedeu-se uma pesquisa descritiva com abordagem quantitativa por meio de análise documental.

A partir dos resultados verificou-se que houve um aumento na divulgação de Relatórios de Sustentabilidade e Relatórios Anuais de um ano para o outro, visto que no ano de 2010 eram apenas 17 e este número foi aumentando gradativamente até chegar a 31 relatórios (RS+RA) que continham ao menos uma informação ambiental sobre transporte no ano de 2013. Conforme Hackston e Milne (1996) desde aquela época já houve um aumento do número de empresas que divulgavam voluntariamente suas atividades em seus relatórios.

Destaca-se em relação aos quatro anos analisados, que 06 das 97 empresas apresentaram informações ambientais sobre o aspecto transporte em todos os anos analisados, sendo estas as empresas: Copel, CPFL Energia, Eletropaulo, Fibria, Natura, P. Açúcar e Petrobras. Este resultado demonstra que tais empresas preocupam-se com o meio ambiente e a sociedade. De acordo com Rosa et al. (2011) a evidenciação ambiental é utilizada para prestar contas à sociedade. Dessa forma, essas empresas apresentam informações sobre este aspecto, visando seu 
reconhecimento e, consequentemente, melhorando a sua imagem. Dentre estas organizações apresentadas, salienta-se que a empresa Copel liderou o ranking no ano de 2010 e 2011. Contudo, o score das empresas (Even e P. Açúcar) que lideraram nos anos 2012 e 2013 foi mais baixo, (próximo de 0,00), o que é considerada a solução ideal de evidenciação ambiental, a partir do método utilizado nesta pesquisa.

Ressalta-se ainda o fato de que nos quatro anos analisados, nem sempre as mesmas empresas estavam presentes nos rankings de evidenciação ambiental, o que demonstra que de um ano para o outro as empresas não preocuparam-se com a continuidade, bem como aprimoramento das informações evidenciadas nos Relatórios de Sustentabilidade e Relatórios Anuais. Outro fato é o baixo nível de evidenciação ambiental apresentado dentre as empresas que continham alguma informação sobre os transportes em seus relatórios. A partir destes resultados notase que as empresas não apresentam uma preocupação constante em divulgar dados sobre os impactos causados por meio da utilização dos transportes e redução destes em seus relatórios.

Conclui-se que, no que diz respeito ao objetivo geral de analisar o nível de responsabilidade social e ambiental das empresas brasileiras frente aos impactos ambientais de transporte evidenciados nos Relatórios de Sustentabilidade e Relatórios Anuais, as empresas, mesmo apresentando um aumento gradativo na divulgação de seus relatórios nos anos analisados, devem se preocupar em divulgar mais informações sobre o aspecto transporte. Isso porque apenas 31 das 97 empresas no ano de 2013 apresentaram ao menos uma divulgação em seus relatórios, o que representa apenas um terço das empresas analisadas. Ressalta-se ainda que em 2013 obteve-se o maior número de relatórios divulgados em relação aos demais anos.

Deste modo, é necessário que as empresas se preocupem mais em apresentar seus impactos e redução destes sobre transporte em seus relatórios, pois a sociedade e governo cobram maior responsabilidade social e ambiental por parte destas. Nesse sentido, Villiers, Low e Samkin (2014) destacam que as pressões incentivam ainda mais as empresas a divulgarem quantidades maiores de informações sobre sustentabilidade.

Com o intuito de aumentar a evidenciação ambiental, as organizações devem divulgar mais informações no que diz respeito principalmente aos critérios 
de avaliação dos impactos, isto é, a divulgação dos critérios utilizados pela empresa para avaliar os impactos dos transportes e, em relação à redução de impactos no que tange as metas, ou seja, a evidenciação ambiental sobre o percentual de metas de redução de impactos de transportes do ano anterior que foram atendidas no último ano. Nesta perspectiva, corroborando com estas afirmações, Peeters, Szimba e Duijnisveld (2007) salientam a importância de incorporar políticas que são destinadas a reduzir o impacto ambiental dos transportes. Além disso, ressalta-se que apenas o critério tipo de informação apresentou a maior evidenciação por parte das empresas analisadas.

No desenvolvimento do estudo verificaram-se algumas limitações em relação à não uniformidade entre os Relatórios Anuais e Relatórios de Sustentabilidade disponibilizados pelas empresas analisadas. Outra limitação é que os resultados obtidos não podem ser generalizados, visto que foram analisadas somente as empresas brasileiras listadas no IBrX-100 da BM\&FBovespa. Como sugestões para pesquisas futuras, recomenda-se a análise sobre o aspecto ambiental transporte de todas as empresas brasileiras listadas na BM\&FBovespa, ou até mesmo da bolsa de valores de outros países. Sugere-se ainda a verificação de outros aspectos relevantes relacionados ao meio ambiente e que constam no GRI.

\section{REFERÊNCIAS}

ALBERTINI, E. A descriptive analysis of environmental disclosure: A longitudinal study of French companies. Journal of Business Ethics, v. 121, n. 2, p. 233-254, 2013.

BOFF, M. L. Estratégias de legitimidade organizacional de Lindblom na evidenciação ambiental e social em relatórios da administração de empresas familiares. 2007. 160 f. Dissertação (Mestrado em Ciências Contábeis) - Universidade Regional de Blumenau, Programa de Pós-Graduação em Ciências Contábeis do Centro de Ciências Sociais Aplicadas, Blumenau, SC.

BORGES, A. P.; ROSA, F. S. da.; ENSSLIN, S. R. Evidenciação voluntária das práticas ambientais: um estudo nas grandes empresas brasileiras de papel e celulose. Produção On Line, v. 20, n. 3, p. 404-417, 2010. 
BRITO, H. P. de. Análise das emissões atmosféricas geradas por veículos automotores na cidade de Natal-RN. 2005. 166 f. Dissertação (Mestrado em Engenharia Mecânica) - Universidade Federal do Rio Grande do Norte, Programa de Pós-Graduação em Engenharia Mecânica, Rio Grande do Norte, RN.

BUHR, N.; FREEDMAN, M. Culture, institutional factors and differences in environmental disclosure between Canada and the United States. Critical Perspectives on Accounting, v. 12, n. 3, p. 293-322, 2001.

COSTA, R. S. da. Evidenciação Contábil das Informações Ambientais: uma análise das empresas do setor de papel e celulose da BOVESPA. 2006. 146 f. Dissertação (Mestrado em Ciências Contábeis e Atuárias) - Pontifícia Universidade Católica de São Paulo - PUC-SP, Programa de Estudos Pós-Graduados em Ciências Contábeis e Financeiras, São Paulo, SP.

CRESPO SOLER, C.; RIPOLL FELIU, V. M.; ROSA, F. S. da.; LUNKES, R. J. Modelo EDE - Environmental Disclosure Evaluation. Quadern de treball. Universitat de València. Facultad de Economía. España, n. 169, p. 1-28, 2011.

DAUB, C.-H. Assessing the quality of sustainability reporting: an alternative methodological approach. Journal of Cleaner Production, v. 15, n. 1, p. 75-85, 2007.

EYRING, V.; ISAKSEN, I. S. A.; BERNTSEN, T.; COLLINS, W. J.; CORBETT, J. J.; ENDRESEN, O.; GRAINGER, R. G.; MOLDANOVA, J.; SCHLAGER, H.; STEVENSON, D. S. Transport impacts on atmosphere and climate: Shipping. Atmospheric Environment, v. 44, n. 37, p. 4735-4771, 2010.

GIL, A. C. Métodos e técnicas de pesquisa social. 6. ed. São Paulo: Atlas, 2010.

GRI - Global Reporting Initiative. Princípios para relato e conteúdo padrão. [S.l.; s.n], 2013.

HACKSTON, D.; MILNE, M. J. Some determinants of social and environmental disclosures in New Zealand companies. Accounting, Auditing \& Accountability Journal, v. 9, n. 1, p. 77-108, 1996.

HARTE, G.; OWEN, D. Environmental disclosure in the annual reports of British companies: a research note. Accounting, Auditing \& Accountability Journal, v. 4, 
n. 3, p. 51-61, 1991.

IATRIDIS, G. E. Environmental disclosure quality: Evidence on environmental performance, corporate governance and value relevance. Emerging Markets Review, v. 14, p. 55-75, 2013.

KRESPI, N. T. Relação entre os rankings formados pelos indicadores de sustentabilidade e pelos indicadores financeiros tradicionais das empresas candidatas ao ISE: uma aplicação dos métodos displaced ideal e displaced ideal modificado. 2012. 101 f. Dissertação (Mestrado em Ciências Contábeis) Universidade Regional de Blumenau, Programa de Pós-Graduação em Ciências Contábeis, Blumenau, SC.

LUNGU, C. I.; CARAIANI, C.; DASCALU, C. New perspectives on corporate reporting: social-economic and environmental information. Theoretical and Applied Economics, v. 11, n. 11, p. 37-42, 2007.

MARCONI, M. A.; LAKATOS, E. M. Fundamentos de metodologia científica. 7. ed. São Paulo: Atlas, 2010.

MENG, X. H.; ZENG, S. X.; TAM, C. M.; XU, X. D. Whether top executives' turnover influences environmental responsibility: From the perspective of environmental information disclosure. Journal of business ethics, v. 114, n. 2, p. 341-353, 2013.

NOSSA, V. Disclosure ambiental: uma análise do conteúdo dos relatórios ambientais de empresas do setor de papel e celulose em nível internacional. São Paulo, 2002. 249 f. Tese (Doutorado em Ciências Contábeis) - Programa de PósGraduação em Ciências Contábeis, Departamento de Contabilidade e Atuária, Faculdade de Economia, Administração e Contabilidade da Universidade de São Paulo, São Paulo, SP.

OLIVEIRA,A. F. de.; MACHADO, D. G; BEUREN, I. M. Disclosure Ambiental de Empresas de Setores Potencialmente Poluidores Listadas no Índice de Sustentabilidade Empresarial (ISE). Revista de Gestão Social e Ambiental, v. 6, n. 1, p. 20-37 2012.

PEETERS, P.; SZIMBA, E.; DUIJNISVELD, M. Major environmental impacts of European tourist transport. Journal of Transport Geography, v. 15, n. 2, p. 83-93, 2007.

RICHARDSON, R. J. Pesquisa Social: métodos e técnicas. São Paulo: Atlas, 1989. 
ROSA, F. S. da.; LUNKES, R. J.; HEIN, N.; VOGT, M.; DEGENHART, L. Analysis of the determinants of disclosure of environmental impacts of Brazilian companies. Global Advanced Research Journals, v. 3, n. 6, p. 249-266, 2014.

SAID, R.; OMAR, N.; ABDULLAH, W. N. Empirical investigations on boards, business characteristics, human capital and environmental reporting. Social Responsibility Journal, v. 9, n. 4, p. 534-553, 2013.

TSAMBOULAS, D.; MIKROUDIS, G. EFECT-evaluation framework of environmental impacts and costs of transport initiatives. Transportation Research Part D: transport and environment, v. 5, n. 4, p. 283-303, 2000.

UHEREK, E.; HALENKA, T.; BORKEN-KLEEFELD, J.; BALKANSKI, Y.; BERNTSEN, T.; BORREGO, C.; GAUSS, M.; HOOR, P.; JUDA-REZLER, K.; LELIEVELD, J.; MELAS, D.; RYPDAL, K.; SCHMID, S. Transport impacts on atmosphere and climate: Land transport. Atmospheric Environment, v. 44, n. 37, p. 4772-4816, 2010.

VIEIRA, J.; MOURA, F.; VIEGAS, J. M. Transport policy and environmental impacts: The importance of multi-instrumentality in policy integration. Transport Policy, v. 14, n. 5 , p. $421-432,2007$.

VILLIERS, C. de.; LOW, M.; SAMKIN, G. The institutionalisation of mining company sustainability disclosures. Journal of Cleaner Production, v. 84, p. 1-8, 2014.

ZELENY, M. A concept of compromise solutions and the method of the Displaced ideal. Computers \& Operations Research, v. 1, n. 3-4, p. 479-496, 1974.

ZELENY, M. Multiple criteria decision making. New York: McGraw-Hill, 1982.

Recebido em: 11 de março de 2015 Revisado em:17 de setembro de 2015 Aceito em: 22 de dezembro de 2015 